\title{
Dinámica de la fenología de la vegetación a partir de series temporales de NDVI de largo plazo en la provincia de La Pampa
}

\author{
Pablo VÁzquez ${ }^{\varpi}$; Eduardo Adema \& Beatriz Fernández \\ INTA, EEA Guillermo Covas, Área de Gestión Ambiental y Recursos Naturales
}

\begin{abstract}
RESUMEN. La cubierta vegetal es un indicador natural de la salud ambiental y tendencia climática, y la actividad fotosintética permite detectar esas variaciones. No obstante, su evaluación a escala de región es una tarea complicada debido a la escasez de inventarios multitemporales. La teledetección ha facilitado el estudio de la dinámica y distribución espacial de la vegetación a partir de un estimador del índice de área foliar y de la fracción de la radiación fotosintéticamente activa interceptada, conocido como índice verde normalizado (NDVI). La provincia de La Pampa cuenta con un estudio de composición y distribución florística a escala de paisaje y región, donde se reconocen procesos de degradación. El objetivo de este trabajo fue caracterizar la dinámica de la cubierta vegetal de la provincia de La Pampa mediante el análisis de series temporales de NDVI de largo plazo con diferentes resoluciones espaciales y temporales (MODIS y NOAA GIMMS). Específicamente identificamos patrones temporales de NDVI, determinamos su biometría típica, su variabilidad bajo condiciones de disponibilidad hídrica contrastante y evolución del NDVI durante los últimos 31 años. Se detectaron 24 patrones temporales que fueron reagrupados en 8 grupos según su componente botánico más representativo. Se definieron los parámetros biométricos típicos para cada patrón temporal y se cuantificó su variación bajo condiciones de estrés hídrico. Se detectaron aumentos del NDVI en el oeste de la provincia, en coincidencia con la degradación de esos ambientes por arbustización. En el sudeste, y sobre toda la zona cubierta por la isohieta de $500 \mathrm{~mm}$, se identificaron reducciones significativas del NDVI, producto del desmonte. También se detectó una reducción significativa en el noreste, también provocada por un cambio en el uso de la tierra.
\end{abstract}

[Palabras clave: patrones temporales, biometría, NOAA, MODIS, degradación ambiental, cambio climático]

\begin{abstract}
Aвstract. Vegetation phenology dynamics from long term NDVI time series in La Pampa province: Plant structure and function are natural indicators of environmental health and climatic trends, since photosynthetic activity allows to detect spatial and temporal variation. The evaluation of these trends at a regional scale is a challenging task due to shortages of multi-temporal inventories. Remote sensing has simplified the study of spatial distribution and dynamics of vegetation from an estimator of leaf area index and fraction of photosynthetically active radiation intercepted, known as the Normalized Green Index (NDVI). La Pampa province has a study of floristic composition and distribution at the landscape and regional scales, where degradation processes were recognized. The objective of this work was to characterize vegetation cover dynamics in La Pampa province from long term NDVI time series analysis, with different spatial and temporal resolution (MODIS and NOAA GIMMS). We specifically identified temporal NDVI patterns, characterized their typical biometrics, their variability under contrasting water availability and NDVI evolution over the last 31 years. Twenty four temporal patterns were detected and re-grouped into 8 clusters according to their most representative botanical component. Typical biometric parameters were defined for each group and significant changes were found for them under water stress condition. Photosynthetic activity increments were detected in the west of the province, consistent with shrubbing degradation processes. In the southeast and over the entire $500 \mathrm{~mm}$ isohyet region, significant reductions in the NDVI were identified process compatible with wood logging and shrubs clearance. We also detected a significant fall in the northeast NDVI, also compatible with changes in land use.
\end{abstract}

[Keywords: temporal patterns, biometrics, NOAA, MODIS, environmental degradation, climatic change]

\section{INTRODUCCIÓN}

La vegetación es un indicador primordial del estado de un ecosistema por su papel fundamental en los ciclos del agua y del carbono y por la información que provee para la comprensión del cambio climático (Sobrino \& Julien 2011). La actividad fotosintética es una medida de la transformación de la energía radianteen energía química, ycualquiercambio observable en ella puede indicar alteraciones en el ambiente (Baldi et al. 2008). Sin embargo, la evaluación de dichos cambios, a escala de región o continental, es una tarea difícil debido

$\bowtie$ pvazquez@anguil.inta.gov.ar a la escasez de inventarios multitemporales y su limitada cobertura espacial.

Durante los últimos cuarenta años, la teledetección ha facilitado el estudio de la dinámica y distribución espacial de la vegetación. Existen numerosos índices espectrales que permiten resumir la información provista por los sensores remotos. Dentro de ellos, uno de los más utilizados es el NDVI, que relaciona la información espectral de la región del rojo y el infrarrojo cercano del espectro electromagnético (Rouse 1974). Si

Recibido: 27 de noviembre de 2012; Fin de arbitraje: 17 de marzo de 2013; Revisión recibida: 16 de abril; Aceptado: 25 de mayo. 
bien no es un buen estimador de la actividad fotosintética (Gamon et al. 1995), el NDVI está asociado significativamente al índice de área foliar y a la fracción de la radiación fotosintéticamente activa interceptada (Law \& Waring 1994). La fenología de la cubierta vegetal también está relacionada el NDVI, por lo cual se la puede analizar a través de una serie de tiempo obtenida por sensores remotos y estimar parámetros biométricos que caracterizan a las diferentes etapas de un ciclo fenológico (Reed et al. 1994; Goetz 1997; Tieszen et al. 1997; Boles 2004; Jönsson \& Ecklhund 2004; Mattar et al. 2008).

El sensor Advanced Very High Resolution Radiometer (AVHRR), montado sobre la serie de satélites de la National Oceanic and Atmospheric Administration (NOAA), provee desde 1978 la serie temporal más larga de datos satelitales con información superficial y atmosférica (Kidwell 1991). Estas series temporales largas de NDVI, caracterizadas por su baja resolución espacial (píxel de $8 \times 8$ km) y resolución temporal elevada (composiciones cada 15 días) son una herramienta muy importante para detectar tanto cambios abruptos (e.g., deforestación, incendios) como graduales, debidos, por ejemplo, a cambios registrados en la estacionalidad y magnitud de las precipitaciones, producto del cambio climático (Baldi et al. 2008; Al-Qinna et al. 2011; Sobrino \& Julien 2011). Si bien estas series de datos presentan limitaciones por la degradación y la descalibración de los sensores, la contaminación atmosférica y la deriva orbital, esfuerzos exitosos por mejorar su calidad originaron nuevas series como las PAL Pathfinder AVHRR (James \& Kalluri 1994), Global Inventory Monitoring and Modelling Studies (GIMMS) (Tucker et al. 2005) y el Fourier-Adjustment Solar zenith corrected Interpolated and Reconstructed series (FASIR) (Sellers 1994). Varios autores han evaluado la calidad de estas series a escala continental o global (Baldi et al. 2008; de Jong et al. 2011; Sobrino \& Julien 2011). La serie GIMMS muestra un buen comportamiento, en especial en regiones semiáridas (Fensholt et al. 2009).

En Argentina existen numerosos mapeos regionales de comunidades vegetales e inventarios florísticos (Cabrera 1953, 1976; Covas 1964; Veervoorst 1967; León et al. 1979; Cano 1988; Batista et al. 1988; Burkart et al. 1990, 1998). La provincia de La Pampa cuenta con un estudio de composición y distribución florística a escala regional, que si bien es exhaustivo en su descripción y relación con el ambiente, es estático (INTA et al. 1980). A partir de la década de 1990, Paruelo et al. (1998, 2001) identificaron a escala de región y continental tipos funcionales de ecosistemas y describieron su biometría típica a partir del análisis de series temporales de NDVI e identificaron sus patrones temporales típicos. Sin embargo, este tipo de caracterización sigue siendo estática ya que no contempla la variabilidad de los parámetros biométricos frente a variaciones ambientales, como por ejemplo sequías. Otros autores se han enfocado en el estudio de la evolución del NDVI para estimar la dinámica del índice de área foliar, captura y fijación de carbono, producción de biomasa, o para detectar cambios en el funcionamiento de los biomas (Baldi et al. 2008; Donohue et al. 2009; Gamon et al. 1995; Paruelo et al. 2004). Todos estos trabajos incluyen de manera parcial a la provincia de La Pampa, por lo cual la realización de un trabajo que abarque todos los aspectos anteriormente mencionados sería necesaria para interpretar la dinámica de sus comunidades.

La degradación del ambiente es un aspecto relevante en esta región. La deforestación intensiva a asociada a la industria maderera y al avance de la frontera agrícola perduró hasta 1930. A partir de 1980 se documentaron los primeros procesos de arbustización y erosión, coincidentes con una sobreutilización ganadera y la aplicación de prácticas agrícolas no conservacionistas (INTA et al. 1980; FAO 1993). Estos cambios son responsables, al igual que la precipitación, de cambios observables en la evolución del NDVI. El objetivo de este trabajo fue caracterizar la dinámica de la cubierta vegetal de la provincia de La Pampa, identificando en primer lugar patrones temporales de NDVI. Se analizó su correlación espacial con las cubiertas vegetales descriptas para el área de estudio, se caracterizó la biometría típica y la variabilidad de cada patrón temporal bajo condiciones de disponibilidad hídrica contrastante. Finalmente se analizaron los cambios en la tendencia del NDVI durante los últimos 31 años, relacionándolos con procesos de degradación.

\section{Materiales y MÉTOdos}

\section{Área de estudio}

La provincia de La Pampa abarca una superficie es de 14000000 ha. Su clima es templado, con una temperatura media anual de $14-16^{\circ} \mathrm{C}$, y 
precipitaciones principalmente estivales que van desde los $850 \mathrm{~mm} /$ año en el NE hasta $250 \mathrm{~mm} /$ año hacia el SO. Esto define un gradiente hidrológico subhúmedo-árido, a lo largo del cual se identifican tres regiones fitogeográficas y una serie de suelos genéticamente poco desarrollados, que evolucionan desde Molisoles en el E hasta Aridisoles en el O (INTA et al. 1980).

\section{Obtención de la información}

Para relacionar los patrones temporales con las comunidades vegetales en el área de estudio se digitalizó y georeferenció la carta de vegetación disponible en el inventario integrado de recursos naturales de la provincia de La Pampa a escala 1: 500000 (INTA et al. 1980). Esta distingue 14 clases de cobertura, caracterizadas por una o dos especies dominantes, subdivididas en 27 subclases finales en función de las especies acompañantes y tipo de suelo.

El trabajo a partir de imágenes satelitales se enfocó en dos escalas temporales, con objetivos distintos. La primera parte abordó la dinámica de la cubierta vegetal reciente de la región, para lo cual están disponibles series temporales de NDVI provenientes de sensores remotos con resolución espacial y temporal elevadas. La segunda parte consistió en evaluar la tendencia del NDVI para detectar procesos de degradación o desertificación antiguos. Este punto fue analizado a partir de la serie temporal de NDVI GIMMS. Para el análisis de mayor detalle se utilizó la serie temporal de 276 imágenes del sensor MODIS, producto MOD13Q1 v05, para el período enero 2000-diciembre 2011. Este producto integra imágenes de NDVI cada 16 días por el procedimiento Maximun Value Compositing (Holben 1986), con una resolución espacial de 250 m (píxel de 6.25 ha). Para la identificación de procesos de arbustización-deforestación, se utilizó el producto MOD44 v04 (Vegetation Cover Conversion), que cuantifica la superficie ocupada por leñosas y que fuera diseñado específicamente para identificar patrones de cambio en cobertura (Hanson et al. 2003). Su resolución espacial es de $250 \mathrm{~m}$ y presenta un error global de $15 \%$. Se seleccionaron 256 imágenes (período 2000-2010) y se trabajó con los promedios anuales (11 imágenes). Estas imágenes satelitales fueron provistas por el proyecto Yak Ridge National Laboratory Distributed Active Archive Center (2011). Para el análisis de menor detalle se utilizó la serie temporal de 600 composiciones quincenales de NDVI GIMMS, para el período julio 1981-diciembre 2006 (Tucker et al. 2005). Este producto integra las imágenes diarias de NDVI cada 15 días por el procedimiento Maximun Value Compositing (Holben 1986), con una resolución espacial de $8 \mathrm{~km}$, (píxel de 6400 ha). Las imágenes fueron provistas por el Global Land Cover Facility.

La información regional de precipitación acumulada mensual para el período 1980-2011 fue obtenida a partir de un modelo global de precipitación desarrollado por el Global
Precipitation Climatology Center (GPCC), con $50 \times 50 \mathrm{~km}$ de resolución espacial (Rudolf et al. 2003; Rudolf et al. 2005; Rudolf \& Schneider 2005). Esta información presenta un ajuste adecuado con la información pluviométrica medida en 21 localidades (Administración Provincial del Agua 2011) y la modelada por el GPCC $\left(R^{2}=0.83\right.$, EE valor predicho $=9.1, P<0.00000001$ ) (información suplementaria, Figura S1). La ventaja de este producto es disponer de una serie de datos pluviométricos históricos completos para toda la superficie de la provincia de La Pampa.

\section{Análisis de los datos}

Determinación de Patrones temporales de NDVI. Debido a que el período 2000-2011 resume perfectamente la condición climática media de los últimos 31 años (20\% años muy húmedos, 30\% años muy secos y 50\% de años típicos), se calculó la serie temporal promedio de datos (información suplementaria, Figura S2). Para la determinación de los patrones temporales, se aplicó la técnica de análisis multivariada no jerárquica KMeans (Mc Queen 1967) sobre la serie temporal promedio de NDVI del producto MOD13Q1.

Dado un conjunto inicial de $k$ centroides $\mathrm{m} 1(1), \ldots$ ,mk(1), el algoritmo utiliza una técnica iterativa para asignar cada observación al grupo con la media más cercana (es decir, la partición de las observaciones de acuerdo con el diagrama de Voronoi generado por los centroides. El modelo fue restringido para que no genere grupos con una superficie inferior a $1 \%$ de la superficie total (140000 ha). Por lo tanto, esos píxeles son reasignados considerando la menor distancia euclidiana hacia el centroide del cluster más próximo. El producto resultante fue sometido a un filtro de mediana con una grilla de $5 \times 5$ píxeles para eliminar ruido. Mediante un análisis de correspondencia se compararon los patrones temporales obtenidos con el mapa de comunidades vegetales propuesto en el IRN para verificar el grado de relación existente entre los patrones temporales y la composición florística a escala regional. El procesado de las imágenes satelitales y el análisis estadístico se realizó mediante el programa Idrisi Taiga (C2009 Clark Labs, Clark University, USA).

\section{Determinación de curvas de NDVI y parámetros} biométricos típicos para los diferentes patrones temporales. Se seleccionaron aleatoriamente 2000 puntos para cada patrón temporal de la serie temporal promedio de NDVI (MOD13Q1). Las curvas típicas de NDVI fueron ajustadas aplicando la función Savitsky-Golay, Timesat 3.2 (Jönsson y Eklundh 2004). Este método se basa en el cálculo de una regresión polinomial local (de grado k), con al menos $k+1$ puntos equiespaciados, para determinar el nuevo valor de cada punto (Savitsky \& Golay 1964). El resultado será una función similar a los datos de entrada, pero suavizada. La principal ventaja de esta aproximación es que tiende a preservar características de la distribución inicial tales como los máximos y mínimos relativos, así 
como el ancho de los picos, que normalmente desaparecen con otras técnicas de promediado (como la media desplazada). Sobre estas curvas promedio se derivaron los parámetros biométricos a) inicio de estación de crecimiento (INI), b) fin de estación de crecimiento (FIN), c) momento de máximo NDVI (tMAX), d) NDVI mínimo (MIN), e) NDVI máximo (MAX) y f) integral anual del NDVI (INTEG). Se consideró como inicio de estación de crecimiento cuando el NDVI logró un incremento sostenido de $20 \%$ por encima del NDVI mínimo. Por oposición, el fin de la estación de crecimiento fue definido cuando el NDVI disminuyó de manera sostenida y alcanzó un valor $20 \%$ superior al NDVI mínimo.

Impacto de la sequía sobre los parámetros biométricos de los patrones temporales. Para identificar sitios de muestreo con similar historia pluviométrica, se analizó la tendencia de la precipitación anual para el período 2000-2011 mediante el procedimiento Mann-Kendall (Hirsch \& Slack 1984; Helsel \& Frans 2006), Idrisi Taiga (C2009 Clark Labs, Clark University, USA). El análisis permitió identificar una franja con sentido SO-NE que presentó una significativa disminución del registro pluviométrico anual en la última década (información suplementaria, Figura S3). Dentro de esta área, se seleccionaron al azar 1000 puntos de cada patrón temporal correspondiente a vegetación natural de la serie temporal de NDVI (MOD13Q1) para los períodos julio 2006-junio 2007 (período húmedo) y julio 2008-junio 2009 (período seco). Con ellos se estimaron los parámetros biométricos de los patrones temporales para ambos períodos utilizando la metodología propuesta por Jönsson \& Eklundh (2004), descripta anteriormente. Los resultados fueron comparados mediante un modelo lineal general (@Systat software Inc. 2004).

Control del efecto fuego sobre las curvas de NDVI. Para controlar esta variable en el análisis se identificaron áreas incendiadas durante el período 2000-2011 a partir del producto mensual de detección de fuegos activos MOD14, suministrado por el proyecto NASA Earth Observation con resolución espacial de 10×10 km. La detección de de fuego fue verificada contrastando veinte sitios seleccionados al azar con la casuística de incendios de Defensa Civil, seccional La Pampa. La frecuencia mensual de fuego dentro de cada pixel se calculó a partir de considerar como fuego aquellos píxeles con 50 ha o más de afectación. Las áreas con una frecuencia igual o superior a $4 \%$ (equivalente a 5 incendios durante el período analizado) fueron descartadas del análisis. Se propuso esta línea de corte pues un valor inferior eliminaría del análisis el $80 \%$ de los pastizales psamófilos (Elyonurus sp.), ubicados hacia el $\mathrm{N}$ de la provincia (información suplementaria, Figura S4).

Evolución del NDVI en la provincia de La Pampa. Este punto tuvo por objetivo analizar la tendencia del NDVI en la provincia de La Pampa a tres escalas temporales, para lo cual se analizó la tendencia del NDVI acumulado anual durante los períodos 1982-2011 (30 imágenes), 1982-2006 (25 imágenes) y 2000-2011 (12 imágenes) mediante el procedimiento no paramétrico Mann-Kendall. La selección de estos períodos permitió interpretar el peso relativo que tuvo el proceso generalizado de sequía instalado en la provincia de La Pampa durante el período 2007-2010 sobre la tendencia del NDVI durante los últimos treinta años y evitar confusiones con cambios en el uso del suelo o procesos de degradación. Se utilizaron las series temporales de NDVI GIMMS (período 1982-2006). Para completar la serie histórica y completar el período 2007-2011, se reescalaron espacialmente la serie temporal de NDVI del sensor MODIS, producto MOD13Q1. Si bien las resoluciones espaciales son muy diferentes (pixel de 250×250 m para MODIS y de $8 \times 8 \mathrm{~km}$ para GIMMS), está bien documentada la buena correlación existente entre el NDVI de estos productos para zonas semiáridas (Fensholt et al. 2009).

Para detectar procesos de arbustizacióndeforestación se utilizó la serie temporal del producto MOD44 para identificación de cobertura de leñosas (Hansen et al. 2003). Se analizó la tendencia aplicando el procedimiento no paramétrico Mann-Kendall. Si bien éste es un producto validado a escala global (error $\leq 15 \%$ ), se desconoce la sensibilidad del mismo para arbustos de bajo porte, por lo cual el objetivo de este análisis es identificar la presencia de estos procesos y su importancia relativa en la provincia de La Pampa.

\section{Resultados}

El análisis diferenció 24 patrones temporales (Figura 1). Las áreas dominadas por la agricultura, presentaron 9 variantes, atribuibles a la diversidad de manejos tales como rotaciones o tipo de cultivo, y a la presencia o ausencia de tosca. En contraste, las áreas dominadas por comunidades vegetales naturales presentaron patrones temporales menos fraccionados, mucho más conservadas desde el punto de vista de su dinámica estacional y con un menor número de variantes en los patrones temporales. Las reagrupación de las comunidades vegetales según su componente botánico más representativo y de los patrones temporales según la comunidad identificada con mayor frecuencia, indicó una asociación de Kappa $=0.62$ entre los patrones temporales y las comunidades descriptas a escala 1:500000. Los valores de máxima certeza correspondieron a los patrones asociados a áreas con cultivos sin tosca (80\%), arbustal de Larrea sp. (90\%) y arbustal mixto+Atriplex sp. (70\%) (ver Información Suplementaria Tabla S1). El cultivo realizado en zonas sin tosca, independientemente de las variantes observadas, se caracterizó por su marcada estacionalidad y por presentar el mayor valor 


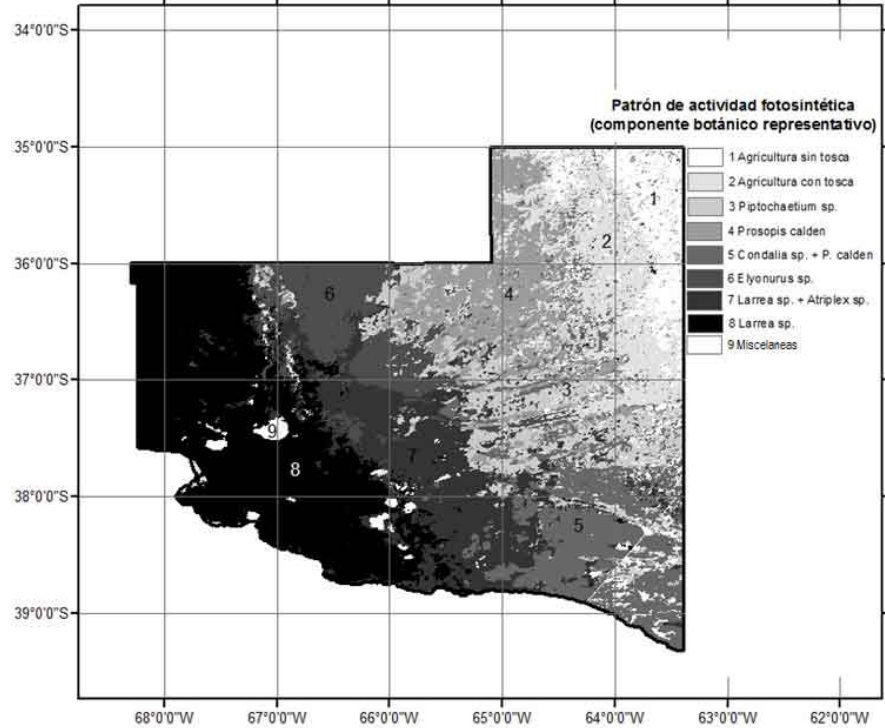

Figura 1. Patrones temporales de NDVI (PT) determinados por la técnica multivariada KMeans y reclasificados por su componente botánico más representativo según la carta de vegetación (INTA et al. 1980), para la provincia de La Pampa.

Figure 1. Temporal NDVI patterns determined by multivariate technique KMEANS and re-classified by their most representative botanical component, according to the vegetation chart (INTA et al. 1980), for La Pampa province. de NDVI máximo y acumulado. Los arbustales de Larrea sp. y mixto+Atriplex sp., ubicados en la zona más árida de la provincia (oeste), presentaron los valores más bajos de NDVI acumulado, lo cual facilitó su identificación. El resto de los patrones temporales presentó certezas inferiores al 60\%, atribuible a la diferencia de escalas existente entre ambas informaciones y a la heterogeneidad intrínseca de estas comunidades. El patrón temporal 18 (Piptochaetium sp.) presentó el valor más bajo de certeza (20\%), pero los componentes señalados como contaminantes (3b1: arbustal mixto y 1: bosque abierto) presentaron especies en común con la comunidad 7a y 7b (pastizal de Piptochaetium sp.), como son el Prosopis caldenia, Stipa sp. y Larrea sp. Esto mismo sucedió con el resto de los patrones, producto de la diferencia de escala existente entre la información de base inicial y la generada a partir de las series temporales de NDVI.

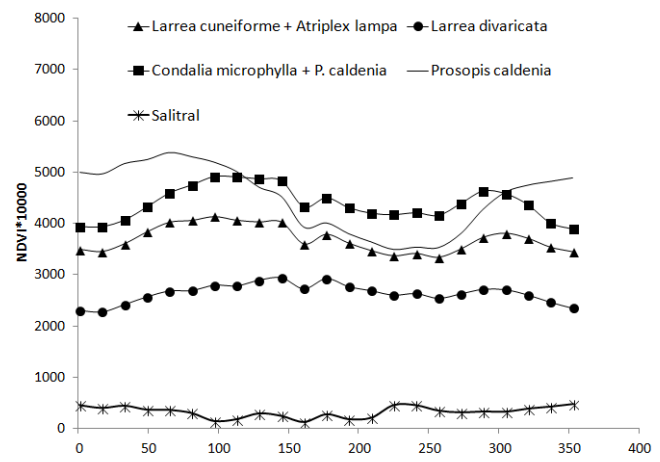

Los patrones temporales presentaron curvas típicas de NDVI unimodales en todos los casos, excepto el asociado a Piptochaetium sp., que presentó bimodalidad. Este último también se caracterizó por ser el de comienzo de ciclo más temprano (inverno-estivo-otoñal), con su máximo NDVI en primavera. Los patrones temporales asociados a cultivos, especies herbáceas y Prosopis caldenia como componente dominante, presentaron un ciclo primaveroestivo-otoñal, con su máximo NDVI en verano. Los dominados por arbustivas perennes (Condalia sp., Larrea sp. y Atriplex sp.), si bien presentaron actividad todo el año, tuvieron su pico de NDVI en otoño. La mayor amplitud, expresada en porcentaje respecto del NDVI mínimo, se observó en los cultivos (38-50\%), seguido por aquellos patrones temporales con un componente herbáceo importante (Elyonurus sp., Piptochaetium sp. y Prosopis caldenia) (30-38\%), finalizando con aquellos

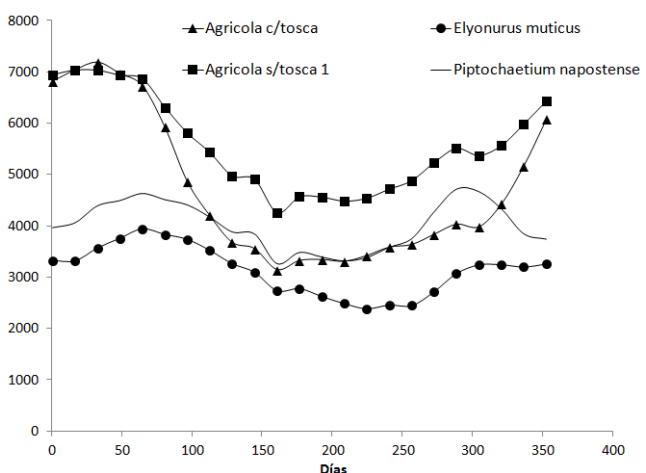

Dias de NDVI (PT) en la provincia Figura 2. Curvas típicas de evolución de NDVI observadas para los patrones temporales de NDVI (P
de la Pampa, reclasificados por su componente botánico más representativo (día $1=1^{\circ}$ de enero).

Figure 2. Typical NDVI evolution curves observed for the temporal NDVI patterns identified in La Pampa province, re-classified by their most representative botanical component (day $1=1^{\text {st }}$ January). 

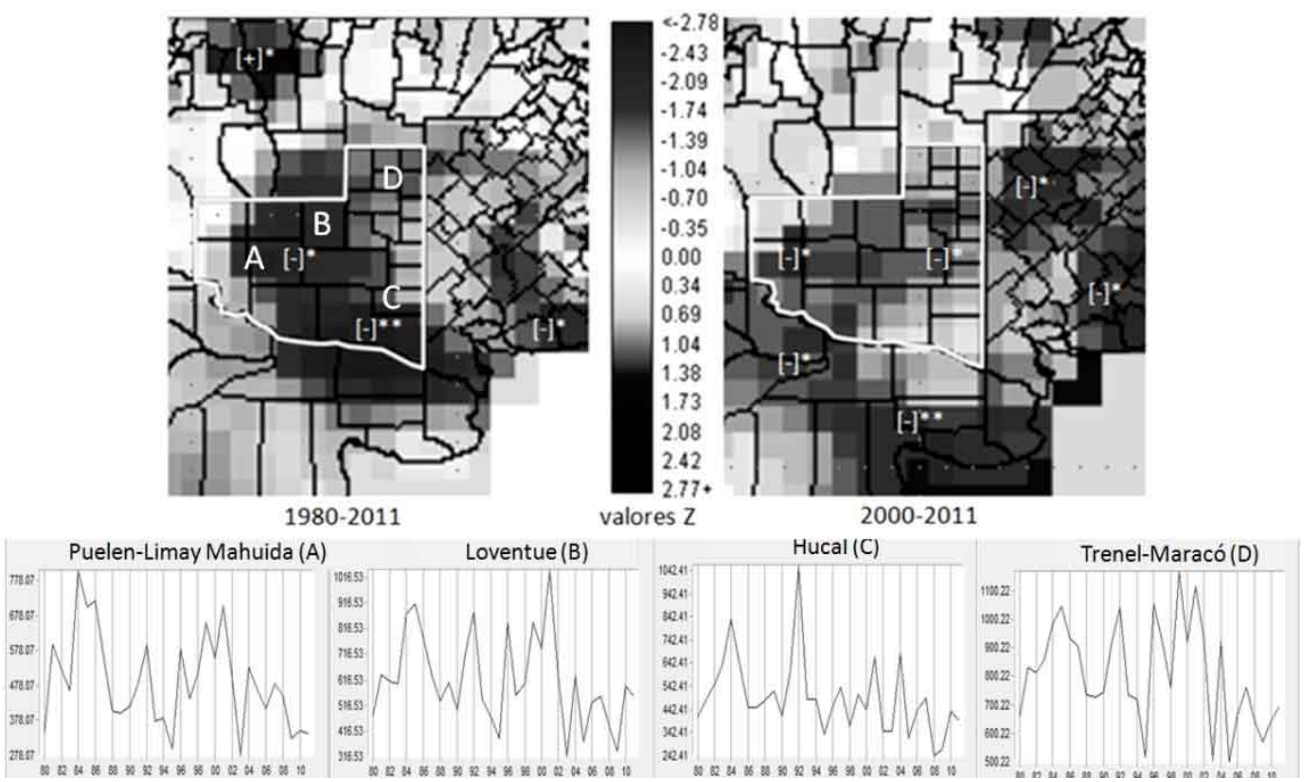

Figura 3. Tendencia de la precipitación anual en la provincia de La Pampa, para los períodos 1980-2011 y 2000-2011, a partir de datos de precipitación modelados por el GPCC. Valores de $Z>1.96([+])$ indican aumento significativo de la pluviometría anual, $\alpha=0.05 ;$ y $Z<-1.96$ ([-]) indican su disminución significativa, $\alpha=0.05$. Detalle de la evolución de la lluvia acumulada anual en cuatro localidades.

Figure 3. Annual precipitation trend and in la Pampa province, for 1980-2011 and 2000-2011 periods, using precipitation data modelled by the GPCC. Values of $Z>1.96([+])$ indicate significant increment of annual accumulated precipitation, and $\mathrm{Z}<-1.96([-])$ indicate significant decrease, $\alpha=0.05$.

dominados por arbustos, con amplitudes inferiores a 20\% (Figura 2, Tabla S2).

La disponibilidad de agua durante la estación de crecimiento afectó de manera significativa la biometría de los patrones temporales. El período húmedo (julio 2006-junio 2007) presentó valores concordantes con una buena disponibilidad hídrica (longitud del ciclo de crecimiento más largo, mayor NDVI basal, NDVI máximo y NDVI acumulado anual)
(Tabla S3). A pesar de ser un período más húmedo, el inicio de la estación de crecimiento se retrasó en promedio 44 días respecto del ciclo seco (julio 2008-junio 2009). Esto fue explicado por el registro de una precipitación elevada durante el período mayo-septiembre, durante el año seco, previo al comienzo de ciclo de crecimiento en todos los patrones temporales (Tabla S3). La excepción fueron los patrones temporales caracterizados por la presencia de Prosopis caldenia (patrones 13,

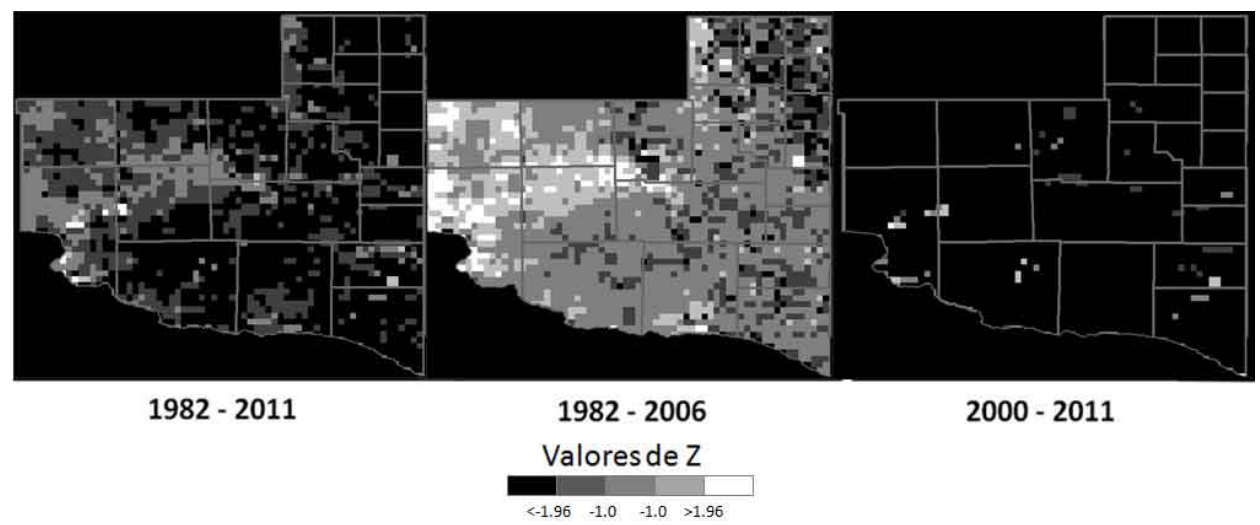

Figura 4. Tendencia del NDVI acumulado anual en la provincia de La Pampa para los períodos 1982-2011, 1982-2006 y 2000-2011, aplicando el modelo Mann-Kendall, utilizando las series temporales de NDVI NOAA GIMMS y MOD13Q1, respectivamente. Valores de $\mathrm{Z}>1.96$ indican aumento significativo del NDVI acumulado anual, y $Z<-1.96$ indican su disminución significativa, $\alpha=0.05$.

Figure 4. Annual accumulated NDVI trend in La Pampa province for 1982-2011, 1982-2006 and 2000-2011 periods appling Mann-Kendall model, using NOAA GIMMS and MOD13Q1 NDVI time-series, respectively. Values of $Z>1.96$ indicate significant increment of annual accumulated NDVI, and $\mathrm{Z}<-1.96$ indicate significant decrease, $\alpha=0.05$. 


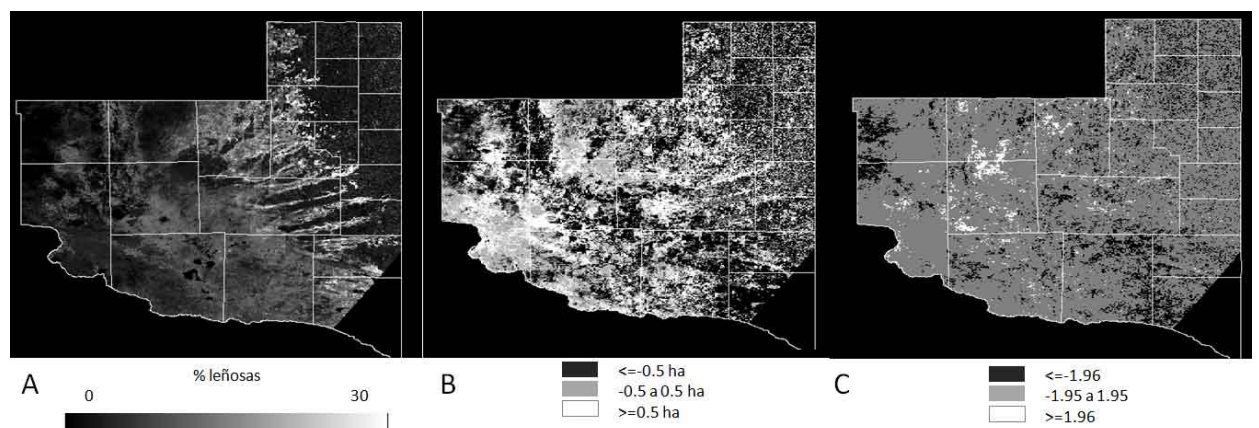

Figura 5. Áreas cubiertas por leñosas identificadas por el producto MOD44 de MODIS Terra: A) porcentaje de leñosas para el año 2010, B) diferencia en la superficie ocupada por leñosas, en hectáreas, período 2000-2010, C) significancia de la diferencia, expresada en valores $Z$.

Figure 5. Woody areas identified by MODIS Terra MOD44 product: A) percentage of woody area, year 2010, B) Woody area difference, in hectares, period 2000-2010, C) Difference significance, expressed in Z scores.

14, 17 y 22) y Larrea cuneifolia+Atriplex lampa (patrones 10 y 11), donde no se observaron diferencias significativas entre las fechas de inicio del período húmedo y seco. Ambos son sistemas dominados por leñosas; en el primer caso, se trata de una especie arbórea con gran capacidad de exploración radical, característico en todos los Prosopis sp. (Burkart 1976), lo cual le permitió superar el período de latencia invernal tomando agua del subsuelo, acumulada durante el período húmedo anterior. El segundo caso está representado por una comunidad arbustiva de gran desarrollo radical, capaz de absorber agua incluso a potenciales osmóticos muy bajos, gracias a su capacidad de acumular sales y forzar el ingreso de agua a las raíces (Passera \& Borsetto 1989; Villagra et al. 2011). Los finales de ciclo de crecimiento se anticiparon en aproximadamente 60 días, con un mínimo de 20 días para el patrón temporal dominado por Elyonurus sp. y un máximo de 94 días para los patrones temporales asociados a Larrea sp. Algo similar ocurrió con el momento de máximo NDVI, que también se anticipó en promedio 60 días.

La tendencia de la precipitación mostró una caída significativa durante la última década (valores de $\mathrm{Z} \leq-1.96$ ) en el eje SO-NE (Figura 3). Esto se condice con una caída del NDVI acumulado anual de la provincia de La Pampa en 12300000 ha durante el período 1982-2011, siendo significativa en 8300000 ha (Figura 4, Tabla S4). Si consideramos el período 1982-2006 (no incluyendo en el análisis la sequía del período 2007-2010, solo 872890 ha disminuyeron de forma significativa el NDVI. Al mismo tiempo, 2400000 ha aumentaron su NDVI, de las cuales 783092 ha lo hicieron significativamente. El análisis del período 2000-2011 confirmó el severo impacto de cinco años de sequía en el análisis de la tendencia en La Pampa, donde el 98\% de la superficie disminuyó significativamente su NDVI.

El análisis de evolución de la cobertura leñosa en la última década, basado en el uso del producto MOD44, detectó 1760000 ha con un aumento significativo en su proporción. Las zonas oeste y central fueron las más afectadas (departamentos de Chalileo, Limay-Mahuida, Utracán, Loventué y Toay) (Figura 5). También se detectaron 311.500 ha donde la proporción de arbustos cayó significativamente. Este hecho fue registrado principalmente en todo el noreste de la provincia (departamento de Rancul), el sudeste (departamentos de Caleu Caleu y Lihuel Calel) y el extremo oeste (departamentos de Puelen y Chical Co).

\section{DisCUSIÓN}

La identificación de patrones temporales en la provincia de La Pampa presenta continuidad con las biozonas halladas por Paruelo et al. (1998) en el norte de la Patagonia, donde los patrones temporales 7 y 8 (arbustales dominados por Larrea sp.) y el patrón temporal 5 (Condalia microphyla+pastizales) presentan su equivalente en las biozonas Jh11 y Hg11, respectivamente. La biometría media de los patrones temporales calculada en este trabajo es concordante con la hallada por Paruelo et al. (2001), a pesar de haber siso calculada con composiciones decádicas NOAA Pathfinder de $64 \mathrm{~km}^{2}$ de resolución espacial. De esta manera, quedaría completa la información de la provincia de La Pampa respecto de biozonas y sus biometrías estimadas a partir de sensores remotos. En la provincia de Mendoza, al norte del área de estudio, González Loyarte et al. (2010) generó un mapa de dinámica vegetal a escala regional a partir de series 
temporales de NDVI GIMMS con resultados compatibles a los hallados en este trabajo. Esto le confiere coherencia regional a todos los estudios realizados en la región centro y sur de Argentina.

El análisis de la tendencia pluviométrica de los últimos 31 años demostró una caída significativa en todo el territorio pampeano, coincidente con la tendencia del NDVI analizada en este trabajo. Estos resultados están muy afectados por la severa sequía del período 2007-2010, por lo cual fue necesario analizar el período 1982-2006, para identificar si esta tendencia es parte de un proceso más antiguo o es el resultado de este período seco. El análisis solo detectó 872890 ha con disminución significativa del NDVI, principalmente en las regiones dominadas por los patrones temporales agrícolas (con y sin tosca), y la zona coincidente con la isohieta de $500 \mathrm{~mm}$ de precipitación media anual. Este comportamiento en la zona agrícola puede explicarse por un incremento sostenido de la superficie sembrada desde 1980 hasta el año 2000, llegando a un máximo de 2500000 ha. El aumento de la superficie agrícola fue acompañado por el aumento de la superficie en barbecho, producto del reemplazo de lotes destinados a trigo, verdeos y pasturas por el cultivo de soja (Carreño \& Viglizzo 2007; Minagri 2012). A partir de 2005, la caída del NDVI fue el resultado de áreas que durante el período de sequía no pudieron ser sembradas. Esta caída, por lo tanto, no estaría reflejando un proceso de degradación sostenido. En la zona dominada por los patrones temporales 6, 7 y 8, dominados por Larrea sp. y Condalia mycrophilla $+P$. caldenia, fueron identificadas 3200000 ha con incremento del NDVI, de las cuales 783097 ha lo hicieron de manera significativa. Este aumento del NDVI es compatible con un proceso de arbustización descripto para esa región (INTA et al. 1980: León \& Aguiar 1985: FAO 1993: Bertiller et al. 1995). El aumento del NDVI es atribuible al sobrepastoreo, producto de un incremento fuerte de la carga animal a partir del año 1977, momento en el que las existencias ganaderas históricas promedio pasaron de 1800000 cabezas (1930-1976) a 3500000 cabezas (19772011) (INTA et al.1980; Minagri 2012). Esto pudo realizarse mediante la transformación del requerimiento energético del ganado ovino (predominante durante la primer mitad del siglo veinte) a su equivalencia en cabezas de ganado bovino, según equivalencias propuestas por Cocimano et al. (1974).
La pérdida de cobertura de leñosas en el noreste responde a un proceso de desmonte por pulsos, provocado por el avance de la frontera agrícola hasta el año 2005, liberando superficie para los cultivos de maní y soja (Carreño \& Viglizzo 2007). El retroceso de las leñosas hacia el sudeste y oeste responde principalmente a la presencia de fuertes incendios ocurridos entre 2001 y 2003 detectados por el análisis de imágenes MOD14 y confirmados por Defensa Civil de La Pampa (comunicación personal). En la región sudeste también se observó desmonte por limpieza de picadas y liberación de lotes para aumentar la capacidad de carga animal.

\section{CONCLUSIONES}

El análisis de series temporales de NDVI de largo plazo para la provincia de La Pampa permitió identificar patrones temporales de NDVI compatibles con las comunidades vegetales descritas en terreno. La sensibilidad de los sensores permitió identificar variantes dentro de una misma comunidad, producto de la interacción entre la proporción de especies en cada sitio ocupado por la comunidad, el tipo de suelo, posición en el paisaje, el clima y uso del suelo. La determinación de los parámetros biométricos de cada patrón temporal permitió definir sus valores medios y estimar el grado de afectación al que se ven sujetos durante períodos de baja disponibilidad hídrica, acortando cinco meses en promedio sus estaciones de crecimiento. El análisis de tendencia del NDVI de los últimos 12 años reflejó una fuerte caída en toda la provincia a consecuencia de la fuerte sequía que afecta a la región desde 2007, y previamente instalada en la región sudeste desde 1994. La utilización de una serie temporal de menor resolución, complementada por las composiciones temporales con mayor detalle, demostró su utilidad para estudiar la dinámica vegetal regional e identificar procesos de degradación y de uso del suelo. Estos resultados, si bien fueron generados a partir del análisis de imágenes de satélite y confrontados con experiencias de otros trabajos, identificaron y cuantificaron situaciones compatibles con las que hasta ahora solo fueron estudiadas puntualmente. El análisis de series de tiempo de NDVI demostró ser sensible a valores extremos, producto en el caso de estudio de la presencia de una sequía prolongada, motivo por el cual deberían ser tenidas en cuenta estas fuentes de variación cuando se analizan áreas extensas. 


\section{BIBLIOGRAFÍA}

Administración Provincial Del Agua (APA). 2011. Datos históricos de lluvia de la provincia de La Pampa. www.apa.lapampa.gov.ar/lluvias/18-informaciongeneral/datos-de-lluvias.html. Última visita: 05-07-2012.

Al-Qinna, M; N Hammouri; M Obediat \& F Ahmad. 2011. Drought analysis in Jordan under current and future climates. Climatic Change, 106:421-440.

Baldi, G; M Nosetto; R Aragón; F Aversa; J Paruelo; et AL. 2008. Long-term satellite NDVI datasets: evaluating their ability to detect ecosystem functional changes in South America. Sensors, 8:5397-5425.

Batista, W; R León \& S Perelman. 1988. Las comunidades vegetales de un pastizal natural de la región de Laprida, prov. de Buenos Aires, Argentina. Phytocoenología, 16: 465-480.

Bertiller, M; N Elissalde; C Rostagno \& G Defosse. 1995. Environmental patterns and plant distribution along a precipitation gradient in western Patagonia. Journal of Arid Environment, 29:85-97.

Boles, S; X XiaO; J Liu; Q Zhang; S Munkhtuya; et Al. 2004. Land covers characterization of Temperate East Asia using multi-temporal VEGETATION sensor data. Remote Sens. Environ., 90:477-489.

Burkart, A. 1976. A monograph of the genus Prosopis (Leguminosae subfam. Mimosoideae). Journal of the Arnold Arboretum, 57:219-525.

Burkart, S; R León; S Perelman \& M Agnusdei. 1998. The grasslands of the flooding Pampa (Argentina): floristic heterogeneity of natural communities of the southern Salado river basin. Coenoses, 13:17-27.

Burkart, S; R León \& C Movia. 1990. Inventario fitosociológico del pastizal de la depresión de Salado (Prov. Bs. As.) en un área representativa de sus principales ambientes. Darwiniana, 30:27-69.

CABrera, A. 1953 Esquema fitogeográfico de la república Argentina. Rev. Museo La Plata (nueva serie) VIII. Botánica, 3:87-168.

CABRERA, A. 1976. Regiones fitogeográficas Argentinas. Enc. Arg. Agr. y Jard. Tomo II, fascículo 2. Acmé. Buenos Aires.

CANO, E. 1988. Pastizales naturales de la Pampa, descripción de las especies más importantes. En Manual de manejo de pastizales naturales en regiones semiáridas, tomo I. Convenio AACREA - provincia de la Pampa. Pp. 425.

Carreño, L \& E Viglizzo. 2007. Provisión de servicios ecológicos y gestión de los ambientes rurales en Argentina. Área Estratégica de Gestión Ambiental. Ediciones INTA, Buenos Aires, Argentina. Pp. 68.

Cocimano, M; A Lange \& E Menvielle. 1975. Estudio sobre equivalencias ganaderas. Bs. As., Argentina. Producción Animal, 4:161-190.

Covas, G. 1964. Los territorios fitogeográficos de de la provincia de la Pampa. Apuntes para la flora de la Pampa nº. Ed. INTA - Anguil.

De Jong, R; S De Bruin; A De Wit; M Schaepman \& D Dent. 2011. Analysis of monotonic greening and browning trends from global NDVI time-series. Remote Sens. Environ., 115:692-702.

Donohue, R; T Mcvicar \& M Roderick. 2009. Climaterelated trends in Australian vegetation cover as inferred from satellite observations, 1981-2006. Global Change Biology, 15(4):1025-1039.

FAO. 1993. Erosión de suelos en la república Argentina. En: Erosión de suelos en América Latina. Taller sobre Utilización de un Sistema de Información Geográfica (SIG) en la Evaluación de la Erosión Actual de Suelos y la Predicción del Riesgo de Erosión Potencial, ISBN 92-854-3001-5.

Fensholt, R; K Rasmussen; T Nielsen \& C Mbow. 2009. Evaluation of earth observation based long-term vegetation trends-intercomparing NDVI time series trend analysis consistency of Sahel from AVHRRR GIMMS, Terra MODIS and SPOT VGT data. Remote Sens. Environ., 113:1886-1898.

Gamon, J; C Field; M Goulden; K Griffin; A Hartley; et Al. 1995. Relationship between NDVI, canopy structure, and photosynthesis in three Californian vegetation types. Ecological Applications, 5:28-41.

GoEtz, S. 1997. Multi-sensor analysis of NDVI, surface temperature and biophysical variables at a mixed grassland site. International Journal of Remote Sensing, 18:71-94.

GonZÁlez Loyarte, M; M Menenti \& F Roig. 2010. Patrones fenológicos de la provincia de Mendoza, Argentina, mediante serie temporal de imágenes NOAA-AVHRR NDVI GAC. Bol. Soc. Argent. Bot., 45:343-362.

Hansen, M; R Defries; G Townshend; M Carroll; C DIMICELI; ET AL. 2003. Global percent tree cover at a spatial resolution of 500 meters: first results of the MODIS vegetation continuous field algorithm. Earth Interactions, 10:1-15.

Helsel, D \& L Frans. 2006. Regional Kendall test for trend. Env. Sci and Tech., 40:4066-4073.

Hirsch, R; J Slack \& R Smith. 1982. Techniques for trend assessment for monthly water quality data. Water Resources Research, 18:107-121.

Holben, B. 1986. Characteristics of Maximum-Value composite image from temporal AVHRR data. International Journal of Remote Sensing, 7:1417-1464.

Inta-Provincia De La Pampa-Universidad Nacional De La PAMPA. 1980. Inventario de los recursos Naturales de la provincia de la Pampa. Segunda ed. Pp. 495 y mapas.

JAMES, M\&S KALLURI. 1994. The Pathfinder AVHRR land data set: An improved coarse resolution data set for terrestrial monitoring. International Journal of Remote Sensing, Special Issue on Global Data Sets, 15(17):3347-3363.

JöNSSON, P \& L EKLUNDH. 2004. TIMESAT-a program for analyzing time-series of satellite sensor data. Computers $\mathcal{E}$ Geosciences, 30:833-845.

KIDWELL, K. 1991. NOAA polar orbital data (TIROS-N, NOAA-6, NOAA-7, NOAA-8, NOAA-9, NOAA-10, NOAA-11 and NOAA-12). Users guide; NOAA/ NESDIS.

LAW, B \& R WARING. 1994. Remote sensing of leaf area index and radiation intercepted by understory vegetation. Ecological Applications, 4:272-279.

León, R \& M Aguiar. 1985. El deterioro por uso pastoril en estepas herbáceas patagónicas. Phytocoenologia, 13: 181-196.

León, R; S Burkart \& C Movia. 1979. Relevamiento fitosociológico del pastizal del norte de la depresión del Salado en La vegetación de la república Argentina. Serie fitogeográfica $\mathrm{n}^{\circ} 17$. Buenos Aires. INTA. Pp. 90.

Mattar, C; J Sobrino; Y Julien; B Franch \& R Oltra. 2008. Método simple para identificación de zonas homogéneas de NDVI y temperatura de superficie en la Península Ibérica. Revista de Teledetección, 30:92-101.

Mc QueEn, J. 1967. Some methods for classification and analysis of multivariate observations. Proceedings of 5-th Berkeley Symposium on Mathematical Statistics and Probability, Berkeley, University of California Press, 1: 281-297. 
Ministerio de Agricultura, Ganadería Y Pesca De La NACIÓn. 2012. Sistema de información integrada agropecuaria: estadísticas on line. www.siia.gov.ar. Ultima visita: 05-10-2012.

Oak Ridge National Laboratory Distributed Active Archive Center (ORNL DAAC). 2011. MODIS subsetted land products, Collection 5. Available on-line daac.ornl.gov/MODIS/modis.html from ORNL DAAC, Oak Ridge, Tennessee, USA. Accessed 03-03-2013.

PARUElo, J; E JobÁggy \& O SAla. 1998. Biozones of Patagonia (Argentina). Ecología Austral, 8:145-153.

Paruelo, J; E JobÁggy \& O SAla. 2001. Current distribution of ecosystem functional types in temperate South America. Ecosystems, 4:683-698.

Paruelo, J; M Garbulsky; J Guerschman \& E JobÁGgy. 2004. Two decades of Normalized Difference vegetation Index change in South America: identifying the imprint of global change. International Journal of Remote Sensing, 25:2793-2806.

Passera, C \& O Borsetto. 1989. Aspectos ecológicos de Atriplex lampa. Investigación Agraria: Producción y Protección Vegetal, 4:179-198.

ReED, B; J BRown; D VANDERZEE; T LOVELAND; J MERCHANT; ET AL. 1994. Measuring phenological variability from satellite imagery. Journal of Vegetation Science, 5:703-714.

Rouse, J; R HaAs; J Schell; D DeERINO \& J Harlan. 1974. Monitoring the vernal advancement of retrogradation of natural vegetation. NASA/OSFC. Type III. Final report. Oreenbello MD. Pp. 371.

Rudolf, B \& U Schneider. 2005. Calculation of Gridded Precipitation Data for the Global Land-Surface using in-situ Gauge Observations, Proceedings of the 2nd Workshop of the International Precipitation Working Group IPWG, Monterey October 2004, EUMETSAT, ISBN 929110-070-6, ISSN 1727-432X, 231-247.
Rudolf, B; C BecK; J Grieser \& U Schneider. 2005. Global Precipitation Analysis Products. Global Precipitation Climatology Centre (GPCC), DWD, Internet publication, 1-8.

Rudolf, B; T Fuchs; U SCHNEIDER \& A Meyer-Christoffer. 2003. Introduction of the Global Precipitation Climatology Centre (GPCC), Deutscher Wetterdienst, Offenbach a. M.; Pp. 16, available on request per email gpcc@dwd.de or by download from GPCC's Website gpcc.dwd.de. Último acceso: 15-12-2012.

SAvitzKy, A \& M Golay. 1964. Smoothing and differentiation of data by simplified least squares procedures. Analytical Chemistry, 36:1627-1639.

SEllers, P. 1994. A global $1^{\circ}$ by $1^{\circ}$ NDVI data set for climate studies. Part 2: the generation of global fields of terrestrial biophysical parameters from the NDVI. International Journal of remote sensing, 15:3519-3545.

SobrinO, J \& Y JULIEN. 2011. Global trends in NDVI-derived parameters obtained from GIMMS data. International Journal of Remote Sensing, 32:4267-4279.

Tieszen, L; B Reed; N Bliss; D De Jong \& B Wylie. 1997. NDVI, C3 and C4 production, and distributions in Great Plains grassland land cover classes. Ecological applications, 7:59-78.

TuCKer, C; J Pinzon; N Brown; DSlaybaCK; E PAK; et Al. 2005. An Extended AVHRR 8-km NDVI Data Set Compatible with MODIS and SPOT Vegetation NDVI data. International Journal of Remote Sensing, 26:4485-4498.

VeERVOORST, F. 1967. Las comunidades vegetales de la depresión del Salado.En La vegetación de la república Argentina. Serie fitogeográfica $n^{\circ} 7$. Buenos Aires. INTA. Pp. 259.

Villagra, P; C Giordano; J Álvarez; J Cavagnaro; A GuEvarA; ET Al. 2011. Ser planta en el desierto: estrategias de uso del agua y resistencia al estrés hídrico en el monte Central de Argentina. Ecología Austral, 21:29-42. 

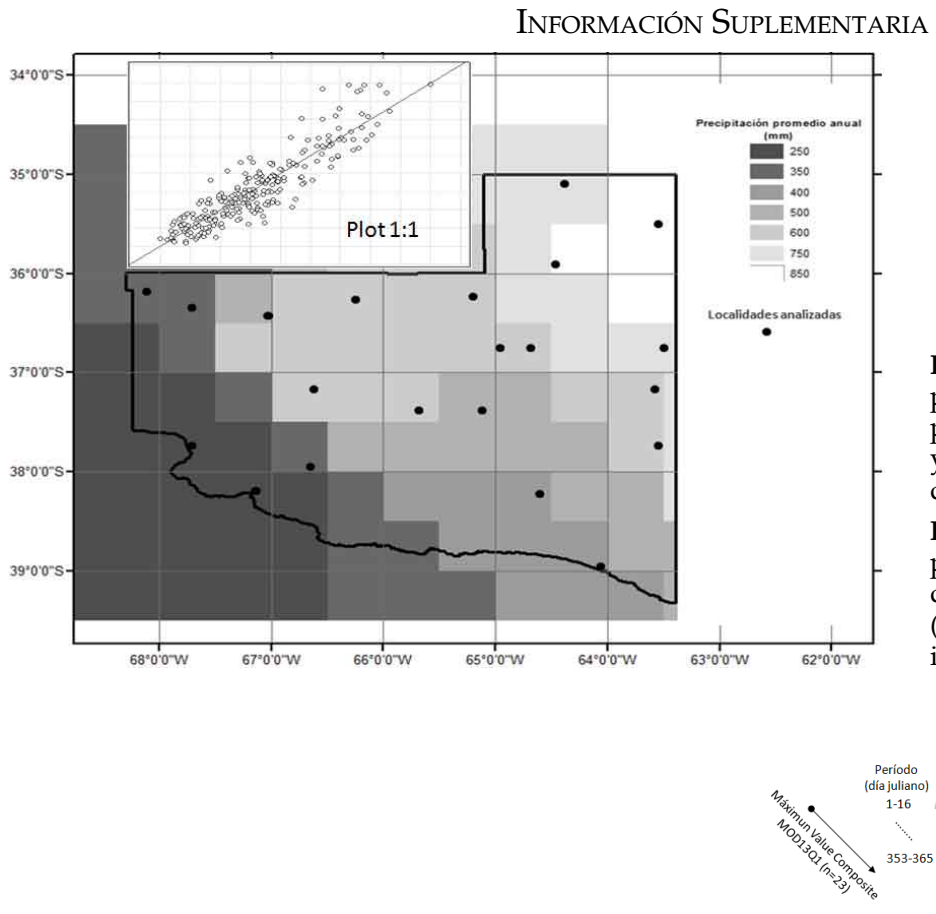

Figura S2. Diagrama de flujo aplicado para el cálculo de patrones teporales de NDVI (PT) en La Pampa.

Figure S2. Applied flowchart for calculating temporal NDVI patterns (PT) in La Pampa.

Figura S3. Determinación de la tendencia de la precipitación anual en la provincia de la Pampa aplicando el modelo Mann-Kendall para el período 2000-2011, a partir de información modelada por el GPCC Valores de Z $>1.96([+])$ indican tendencia positiva significativa de la pluviometría anual, y $Z<-1.96$ ([-]) indican tendencia negativa significativa de la pluviometría anual, $(\alpha=0.05)$. La elipse identifica el área de muestreo.

Figure S3. Determination of annual rainfall tendency in La Pampa province applying Mann-Kendall model for the 2000-2011 period. Values of $Z>1.96([+])$ indicate significant positive annual rainfall tendency, and $\mathrm{Z}<-1.96([-])$ indicate significant negative annual rainfall tendency $(\alpha=0.05)$. Ellipse identifies sampling area.
Figura S1. Precipitación media anual, período 1980-2010, basada en el modelo propuesto por Rudolf y Schneider (2005) y grado de ajuste respecto a información de campo.

Figure S1. Average annual precipitation, period 1980-2010, based on the model developed by Rudolf \& Schneider (2005) and it adjustment respect of field information.

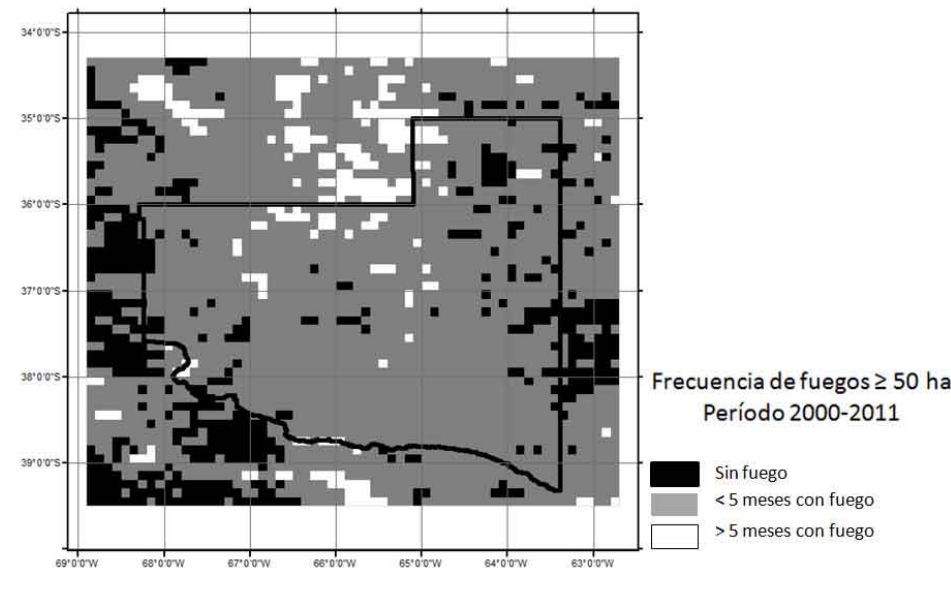

Figura S4. Identificación de áreas con más de 5 incendios en la provincia de La Pampa durante el período 20002011, a partir del producto MOD14.

Figure S4. Identification of areas with more than 5 fires in La Pampa province during the period 2000-2011, from MOD14 product. 
P VÁzQuez et AL.

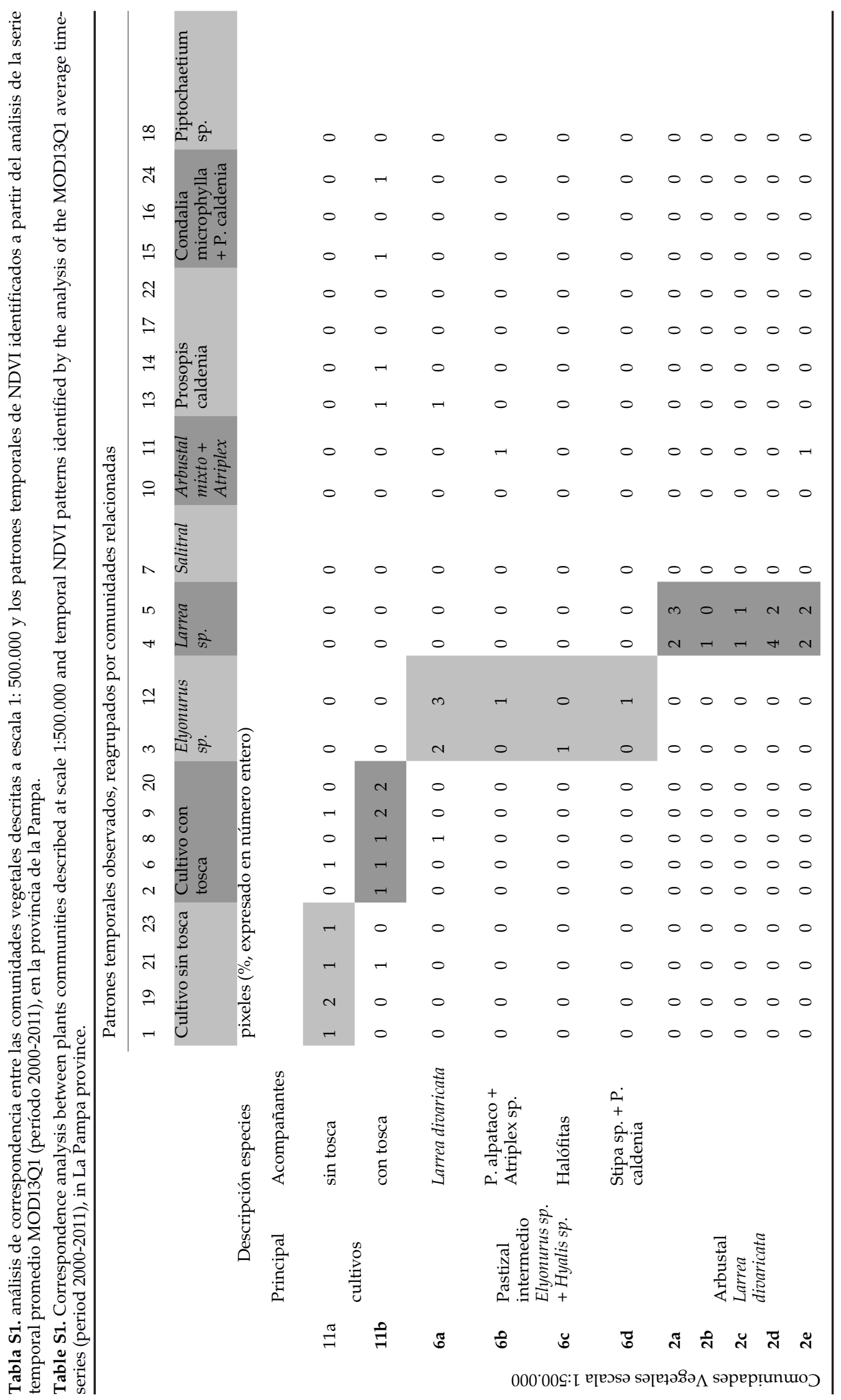




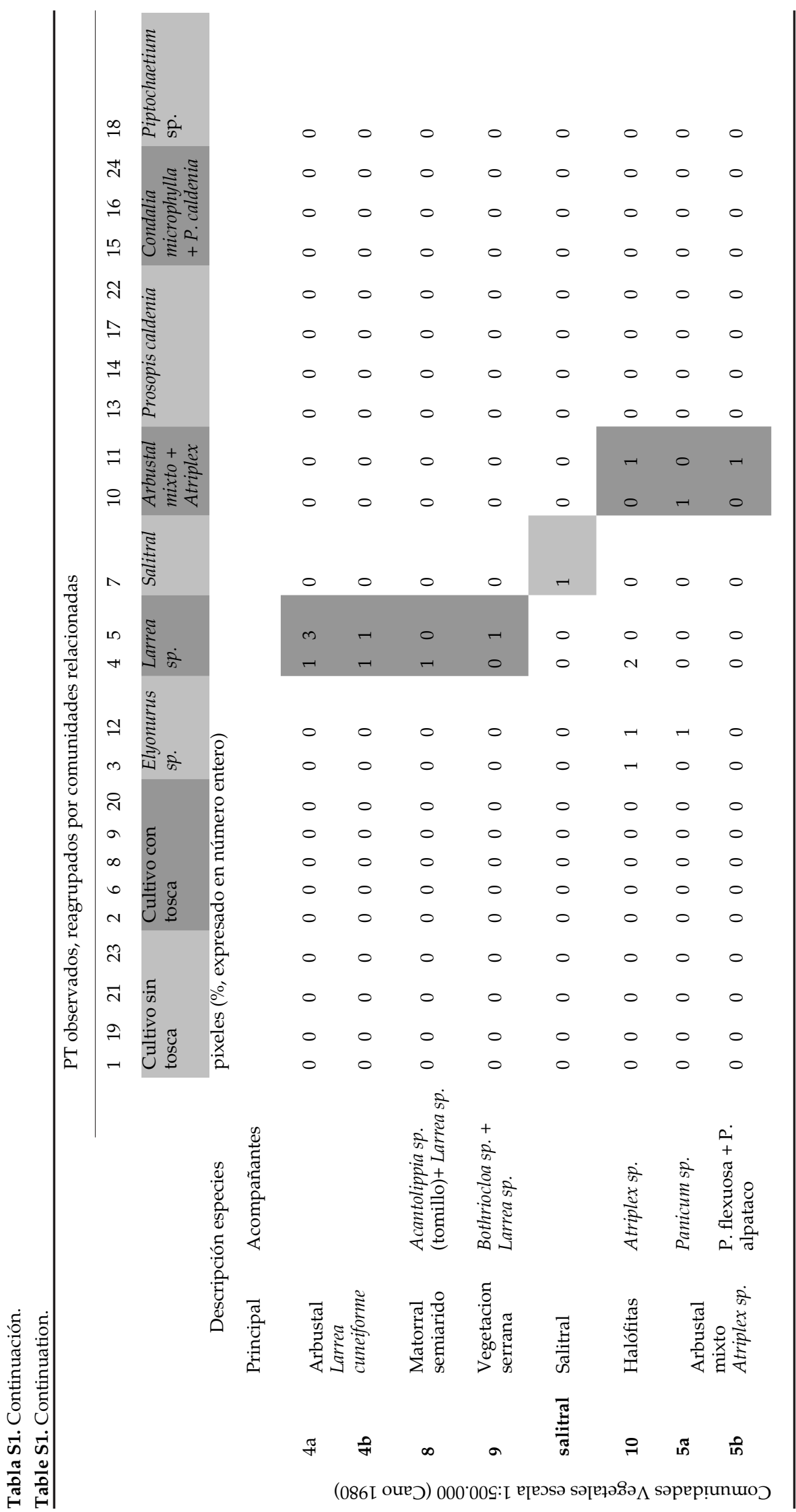




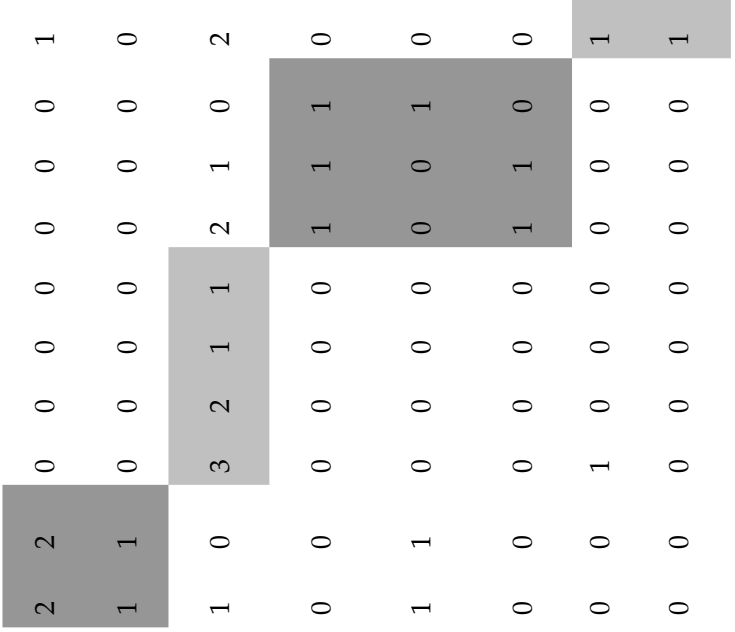

$\begin{array}{lllllllll}0 & 0 & 0 & 0 & 0 & 0 & 0 & 0\end{array}$

$\begin{array}{llllllll}0 & 0 & 0 & 0 & 0 & 0 & 0 & 0 \\ 0 & 0 & 0 & 0 & 0 & 0 & 0 & 0\end{array}$

$\begin{array}{llllllll}0 & 0 & 0 & 0 & 0 & 0 & 0 & 0 \\ 0 & 0 & 0 & 0 & 0 & 0 & 0 & 0\end{array}$

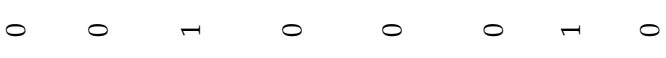

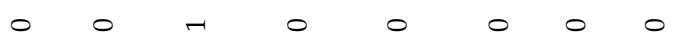

$\begin{array}{llllllll}0 & 0 & - & 0 & 0 & 0 & 0 & 0\end{array}$

$\begin{array}{llllllll}0 & 0 & 0 & 0 & 0 & 0 & 0 & 0\end{array}$

$\begin{array}{llllllll}0 & 0 & 0 & 0 & 0 & 0 & 0 & 0\end{array}$

$\begin{array}{llllllll}0 & 0 & 0 & 0 & 0 & 0 & 0 & 0\end{array}$

$\begin{array}{llllllll}0 & 0 & 0 & 0 & 0 & 0 & 0 & 0\end{array}$

$\begin{array}{llllllll}0 & 0 & 0 & 0 & 0 & 0 & 0 & 0 \\ 0 & 0 & 0 & 0 & 0 & 0 & 0 & 0\end{array}$

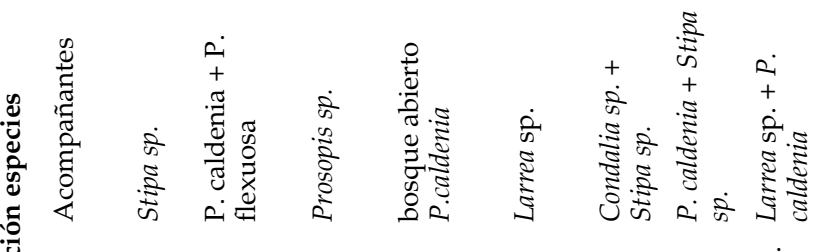

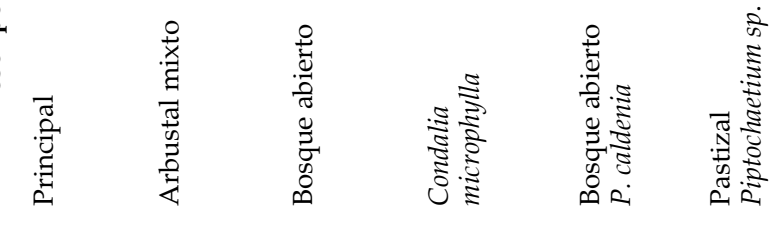

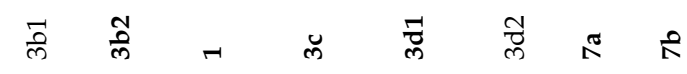


Tabla S2. parámetros biométricos derivados a partir de las curvas de NDVI típicas de los principales patrones de actividad fotosintética (PT) identificados en la provincia de la Pampa, reclasificados por su componente botánico más representativo: inicio de estación de crecimiento (INI), fin de estación de crecimiento (FIN), momento de máximo NDVI (tMAX), NDVI mínimo (MIN), NDVI máximo (MAX) e integral anual del NDVI (INTEG).

Table S2. Biometric parameters derived from typic NDVI curves of the photosynthetic activity patterns identified in La Pampa province, re-classified by their most representative botanical component: start growing season (INI), end growing season (FIN), date of maximum NDVI (tMAX), baseline NDVI (MIN), maximum NDVI (MAX) and annual NDVI integer (INTEG).

\begin{tabular}{|c|c|c|c|c|c|c|c|}
\hline \multirow[t]{2}{*}{ Patrón Temporal } & \multirow{2}{*}{$\begin{array}{c}\text { Superficie } \\
\text { (\%) }\end{array}$} & \multicolumn{6}{|c|}{ Parámetros biométricos } \\
\hline & & \multicolumn{3}{|c|}{ (fecha) } & \multicolumn{3}{|c|}{$(\mathrm{NDVI} * 10000)$} \\
\hline Agrícola s/tosca & 7 & $15 / 09$ & $09 / 05$ & $26 / 01$ & 4502 & 7209 & 102000 \\
\hline Agrícola c/tosca & 11 & $24 / 10$ & $29 / 04$ & $01 / 02$ & 3300 & 7300 & 78000 \\
\hline Elyonurus sp. & 6 & 23/09 & $26 / 06$ & 09/03 & 2440 & 3890 & 65000 \\
\hline Larrea sp. & 26 & 03/02 & $05 / 12$ & $25 / 05$ & 2300 & 2930 & 57000 \\
\hline Arbustal mixto + Atriplex $s p$ & 15 & $20 / 01$ & $28 / 07$ & 07/04 & 3400 & 4200 & 50200 \\
\hline Prosopis caldenia & 12 & $27 / 09$ & 01/07 & $27 / 02$ & 3540 & 5400 & 94000 \\
\hline Condalia microphylla $+P$. caldenia & 10 & 03/02 & 03/12 & $23 / 04$ & 3960 & 4900 & 98000 \\
\hline Piptochaetum sp. & 9 & $29 / 08$ & $10 / 06$ & 22/09 & 3400 & 4650 & 80000 \\
\hline
\end{tabular}

Tabla S3. comparación de parámetros biométricos y precipitación acumulada correspondientes a los períodos húmedo (julio 2006-junio 2007) y seco (julio 2008-junio 2009) para los patrones temporales de NDVI (PT) identificados en la provincia de la Pampa.

Table S3. comparison between biometric parameters and accumulated rain from humid (July 2006-june 2007) and dry (July 2008-june 2009) periods for temporal NDVI patterns identified in La Pampa province.

\begin{tabular}{|c|c|c|c|c|c|c|c|c|c|c|}
\hline \multirow{2}{*}{$\begin{array}{l}\text { PT ( } n=1000 \text { por } \\
\text { PT) }\end{array}$} & \multirow{2}{*}{$\begin{array}{l}\text { Estado } \\
\text { hídrico }\end{array}$} & \multicolumn{3}{|c|}{ Estación de crecimiento } & \multicolumn{3}{|c|}{$\mathrm{NDVI}^{*} 10000$} & \multicolumn{2}{|c|}{$\begin{array}{l}\text { Precipitación } \\
\text { acumulada }(\mathrm{mm})\end{array}$} & \multirow{2}{*}{$\begin{array}{c}\text { Eficiencia } \\
\text { NDVI } \\
\mathrm{mm}^{-1}\end{array}$} \\
\hline & & INI & $\begin{array}{l}\text { (fecha) } \\
\text { FIN }\end{array}$ & tMAX & MIN & MAX & INTEG & $\begin{array}{l}\text { acumulc } \\
\text { may- } \\
\text { sep }\end{array}$ & $\begin{array}{c}\text { da }(\mathrm{mm}) \\
\text { anual }\end{array}$ & \\
\hline \multirow{3}{*}{ Elyonurus sp. } & Húmedo & 17-nov & 03-jul (b) & 09-mar & 1941 (a) & 4487 (b) & $56380 \mathrm{~ns}$ & 14 (a) & 544 (b) & 104 (a) \\
\hline & Seco & 14-sep (a) & 13-jun (a) & 01-feb(a) & 2152(b) & 3450 (a) & $54720 \mathrm{~ns}$ & $65(b)$ & 355(a) & $154(b)$ \\
\hline & Húmedo & 16-ene(a) & 28-ago(b) & 24-abr(b) & 1637(a) & 3781(b) & 47420(b) & 95(a) & $407(b)$ & 117(a) \\
\hline Larrea sp. & Seco & 20-oct(b) & 26-may(a) & 07-mar(a) & 1988(b) & 2790(a) & 44490(a) & $162(b)$ & 283(a) & 157(b) \\
\hline \multirow{3}{*}{$\begin{array}{l}\text { Arbustal mixto.+ } \\
\text { Atriplex sp. }\end{array}$} & Húmedo & 01-nov & 09-ago & 25-mar & 2483(b) & $5045(b)$ & $76900(b)$ & $19(\mathrm{a})$ & $516(b)$ & 149(a) \\
\hline & Seco & 11-oct & 12-may & 18 -feb & 2811(a) & $4006(a)$ & 66140(a) & $81(\mathrm{~b})$ & $317(a)$ & 209(b) \\
\hline & Húmedo & 09-oct & 15-jul(b) & 26-abr(b) & 3138(b) & 6866(b) & $95250(\mathrm{~b})$ & 11(a) & $599(b)$ & 159(a) \\
\hline Prosopis caldenia & Seco & 03-oct & $16-\operatorname{may}(\mathrm{a})$ & 10-ene(a) & 2967(a) & 6248(a) & 79060(a) & 63(b) & 351(a) & $225(b)$ \\
\hline \multirow{3}{*}{$\begin{array}{l}\text { Condalia } \\
\text { microphylla }+P \\
\text { caldenia }\end{array}$} & Húmedo & 01-nov(b) & 31-jul(b) & $05-a b r(b)$ & 3060(b) & $7205(b)$ & 95980(b) & 21(a) & $500(b)$ & 192(a) \\
\hline & Seco & 16-oct(a) & 04-jun(a) & 28-ene(a) & $2748(a)$ & 6067(a) & $81020(a)$ & 75(b) & $248(\mathrm{a})$ & $327(b)$ \\
\hline & Húmedo & 31-dic(b) & 12 -ago(b) & 08-abr(b) & 2501(b) & $6168(b)$ & 84820(b) & 21(a) & $500(b)$ & 170(a) \\
\hline Piptochaetium sp. & Seco & $28-\operatorname{oct}(\mathrm{a})$ & 13-jun(a) & 09-feb(a) & 2405(a) & 6069(a) & 67300(a) & 75(b) & 248(a) & 271(b) \\
\hline
\end{tabular}

Tabla S4. Tendencia del NDVI en la provincia de la Pampa cuantificada por el procedimiento Mann-Kendall para los períodos 1982-2011, 1982-2006 y 2000-2006, expresada en hectáreas. Valores Z indican tendencia del NDVI (+ o-) y $\mathrm{Z}=0$ corresponde a áreas sin cambio evidente. $\left({ }^{*}=\alpha 0.05\right)$.

Table S4. NDVI tendecy in La Pampa province, quantified by Mann-Kendall procedure for periods 1982-2011,19822006 and 2000-2006, expresed in hectares. Z values indicate NDVI tendency (+ or -) and 0 correspond to areas without evident change. $\left({ }^{*}=\alpha 0.05\right)$.

\begin{tabular}{lccc}
\hline$Z$ & 1982_2011 & 1982_2006 & 2000_2011 \\
\hline & \multicolumn{3}{c}{ Hectáreas } \\
$-1.96^{*}$ & 8318400 & 872891 & 13740568 \\
-1 & 3945171 & 2383063 & 171875 \\
0 & 1617538 & 7584265 & 4975 \\
1 & 61963 & 2376684 & 77398 \\
$1.96^{*}$ & 56928 & 783098 & 5184 \\
\hline
\end{tabular}

